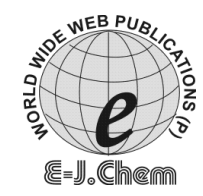

http://www.e-journals.net

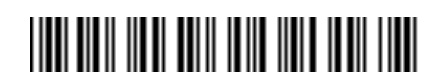

ISSN: 0973-4945; CODEN ECJHAO

E-Journal of Chemistry

Vol. 4, No. 3, pp. 385-389, July 2007

\title{
Studies on Novel Bisaryl Hydrazino-s-triazine Derivatives - Part 2
}

\author{
J. A. CHAUDHARI*, R. P. PATEL ${ }^{\#}$ and M. V. HATHI ${ }^{\dagger}$ \\ *Shri R. K. Parikh Arts \& Science College, Petlad-388450. Gujarat, India. \\ ${ }^{\#}$ C. U. Shah Science College, Ahmedabad-380014. Gujarat, India. \\ 'R. R. Mehta College of Sci. \& C. L. Parikh College of Commerce, \\ Palanpur-385001. Gujarat, India.
}

Received 22 December 2006; Accepted 8 February 2007

\begin{abstract}
Various 2(4-chloro phenyloxy)-4,6-bisarylhydrazino-1,3,5triazines(3a-f) were prepared by reaction of 2(4-chloro phenyloxy)-4,6dichloro -1,3,5-triazine and various aryl hydrazine derivatives. All the 3a-f derivatives were characterized by elemental analysis and IR spectral studies. All the compounds were screened for microbial activity against gram-positive and gram-negative bacteria.
\end{abstract}

Keywords : 2(4-Chloro phenyloxy) bisarylhydrazino s-triazine derivatives, Hydrazines, IR and Spectral study, Antimicrobial activity.

\section{Introduction}

Number of derivatives containing $s$-triazine ring have been reported as hetrocyclic compounds ${ }^{1}$. They are applicable mostly as reactive dyes and some are used as polymers and drugs $s^{2,3}$. The aryl hydrazine derivatives containing $s$-triazine ring are not reported so far except one instance ${ }^{4}$. Recently our university scientists have studied the hydrazine triazine clubbed molecules having alkoxy group ${ }^{4}$. In extension of this work ${ }^{4}$, the present authors reported the novel hydrazine-s-triazine compounds ${ }^{5}$. In continues of this work the present communications deals with the studies on novel s-triazines derivatives having the route shown in scheme-1. 


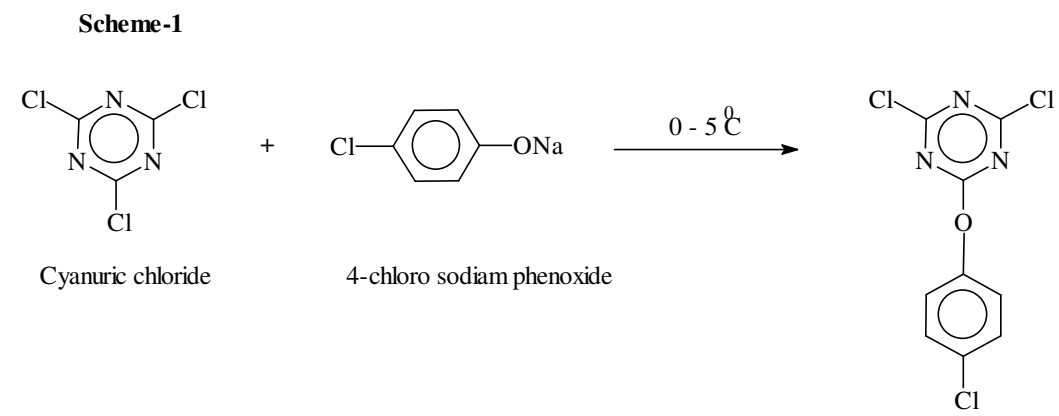

2(4-chloro phenyloxy) dichloro-1,3,5-triazine

Structure - 1

Characterization of 2(4-chloro phenyloxy) -4,6- bisaryl hydrazino -1,3,5-triazine (3a-f)

Aryl hydrazine(Excess)

$+\quad(2 \mathrm{a}-\mathrm{f})$

$\mathrm{K}_{2} \mathrm{CO}_{3}$

( Room temp.)
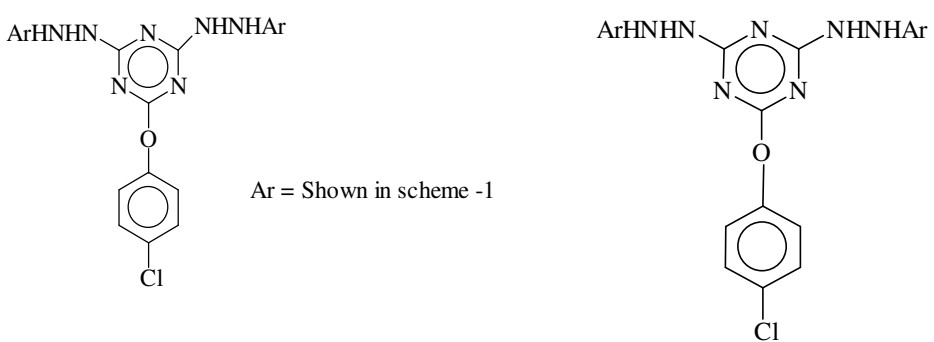

2(4-chloro phenyloxy)-4,6- bisaryl hydrazino-1,3,5-triazine

Where, $\mathrm{Ar}$ :

(3a-f)

a:

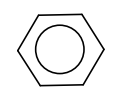

b:

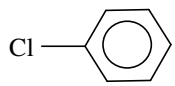

c:

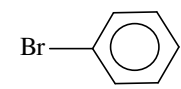

d:

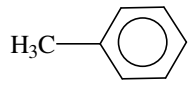

e:<smiles>COc1ccccc1</smiles>

f:

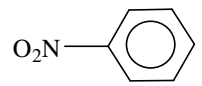

\section{Experimental}

Cyanuric chloride and all the aryl hydrazine derivatives (substitution shown in scheme-1) were obtained as Analar grade from local dealer. 2(4-Chloro phenyloxy)-4,6-dichloro -1,3,5-triazine was prepared by reported method ${ }^{4}$. All other chemicals used were of laboratory grade.

\section{Synthesis of 2(4-chloro phenyloxy) bisaryl hydrazino-s-triazines}

2(4-Chloro phenyloxy)-4,6-bisaryl hydrazino-1,3,5-triazines (3a-f). The general procedure for these compounds is as follows.

To a well stirred solution of 2(4-chloro phenyloxy) -4,6-dichloro-1,3,5-triazine (0.01 mole) in tetrahydrofuran (THF) solvent $(50 \mathrm{~mL})$ a solution of aryl hydrazine (or substituted 
aryl hydrazine) (scheme-1) $(0.02 \mathrm{~mole})$ in THF $(50 \mathrm{~mL})$ was added gradually at room temperature. The mixture was stirred for two hours. Then the mixture was refluxed for further two hours. The resultant solid product was filtered, washed with THF and air-dried. All the (3a-f) compounds listed in Table-1 are dark yellow amorphous powders. Their molecular weights are shown in Table-1.

Table 1. Analysis of synthesized compounds

\begin{tabular}{|c|c|c|c|c|c|c|c|c|}
\hline \multirow[b]{2}{*}{ Compound } & \multirow{2}{*}{$\begin{array}{l}\text { Molecular } \\
\text { Formula }\end{array}$} & \multirow{2}{*}{$\begin{array}{l}\text { Mol. } \\
\text { Weight }\end{array}$} & \multicolumn{2}{|c|}{$\% \mathrm{C}$} & \multicolumn{2}{|c|}{$\% \mathrm{H}$} & \multicolumn{2}{|c|}{$\% \mathrm{~N}$} \\
\hline & & & Cald. & Found & Cald. & Found & Cald. & Found \\
\hline $3-a$ & $\mathrm{C}_{21} \mathrm{H}_{18} \mathrm{~N}_{7} \mathrm{ClO}$ & 419.5 & 60.07 & 60.0 & 4.29 & 4.2 & 23.36 & 23.3 \\
\hline $3-b$ & $\mathrm{C}_{21} \mathrm{H}_{16} \mathrm{~N}_{7} \mathrm{Cl}_{3} \mathrm{O}$ & 488.5 & 51.59 & 51.5 & 3.28 & 3.2 & 20.06 & 19.9 \\
\hline $3-c$ & $\mathrm{C}_{21} \mathrm{H}_{16} \mathrm{~N}_{7} \mathrm{ClBr}_{2} \mathrm{O}$ & 577.5 & 43.64 & 43.6 & 2.77 & 2.7 & 16.97 & 16.9 \\
\hline $3-d$ & $\mathrm{C}_{23} \mathrm{H}_{22} \mathrm{~N}_{7} \mathrm{ClO}$ & 447.5 & 61.68 & 61.6 & 4.92 & 4.8 & 21.90 & 21.8 \\
\hline $3-\mathrm{e}$ & $\mathrm{C}_{23} \mathrm{H}_{22} \mathrm{~N}_{7} \mathrm{ClO}_{3}$ & 479.5 & 57.56 & 57.5 & 4.59 & 4.5 & 20.44 & 20.3 \\
\hline $3-f$ & $\mathrm{C}_{21} \mathrm{H}_{16} \mathrm{~N}_{9} \mathrm{ClO}_{5}$ & 509.5 & 49.46 & 49.0 & 3.14 & 3.0 & 24.73 & 24.6 \\
\hline
\end{tabular}

\section{Mesurements}

The elemental analyses of all (3a-f) compounds were determined by TF flash EA. The FTIR spectra of (3a-f) compounds were scanned in $\mathrm{KBr}$ pallets on Perkin Elmer FT-IR spectrophotometer. The NMR spectra of soluble sample No.3e was scanned on Perkin Elmer FT-NMR spectrophotometer.

\section{Antimicrobial Activity}

For the testing antimicrobial activity various microorganism were used for the study. The pour plate agar method was used for this study. Following general procedure is adopted ${ }^{7}$

The antimicrobial activities of all the compounds were studied at $1000 \mathrm{ppm}$ concentration in vitro. The different types of microorganism used were some gram negative bacteria (Escherichia coli,Proteus valgaris), gram positive bacteria (Bacillus cereus, Streptococus species), fungi (Aspergillus oryzac), yeast (Pichia species) and actinomycetes (Streptomyces coleicor).

The antibacterial activity of 3a-f compounds was measured on each of these microorganism strains on a potato dextrose agar medium (PDA). Such a PDA medium contained $^{5}$ potato $200 \mathrm{~g}$, dextrose $20 \mathrm{~g}$, agar $30 \mathrm{~g}$, and water 1 Litre. PDA medium autoclaved at $121^{\circ} \mathrm{C}$ temperature and $15 \mathrm{lbs}$ pressure for 15 minute. After autoclaving the compounds to be tested were inoculated (1000 ppm) in PDA medium at $42{ }^{\circ} \mathrm{C}$ temperature and mixed, then these media were poured in to sterile empty glass petriplates. The testing microorganism (young culture) were inoculated after solidification of the PDA medium plates. The percentage inhibition of growth of microorganism was calculated after 5 days of incubation of PDA medium plate inoculated with microorganism at appropriate temperature (Bacteria- $37^{\circ} \mathrm{C}$, Fungi- $25^{\circ} \mathrm{C}$, Actinomyces- room temp.) percentage of inhibition of microorganism was calculated by using the formula given below.

$$
\begin{gathered}
\text { Percentage of inhibition of growth of microorganism }=\frac{100(\mathrm{X}-\mathrm{Y})}{\mathrm{X}} \\
\text { Where, } \mathrm{X}=\text { area of bacterial growth in control plate }(\mathrm{mm}), \\
\mathrm{Y}=\text { area of bacterial growth in test plate }(\mathrm{mm}) .
\end{gathered}
$$

The antimicrobial activity of all the $3 \mathrm{a}-\mathrm{f}$ compounds are furnished in Table 2. 
Table 2. Antimicrobial activity of 2 (4-chloro phenyloxy) -4,6- bisaryl hydrazino $-1,3,5$ - triazines ( 3 a to $\mathrm{f}$ )

\begin{tabular}{|c|c|c|c|c|c|c|c|}
\hline \multirow[b]{2}{*}{ 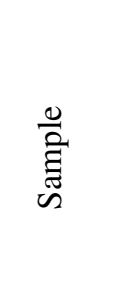 } & \multicolumn{7}{|c|}{$\begin{array}{l}\text { Percentage of inhibition of growth at } 1000 \mathrm{ppm} \\
\text { concentrate of sample, } \%\end{array}$} \\
\hline & 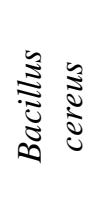 & 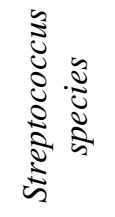 & 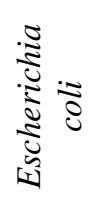 & 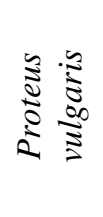 & 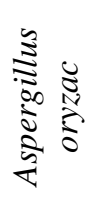 & 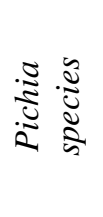 & 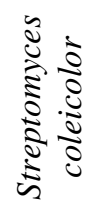 \\
\hline Control & Nil & Nil & Nil & Nil & Nil & Nil & Nil \\
\hline 3-a & 78 & 93 & 92 & 91 & 75 & 78 & 65 \\
\hline $3-b$ & 98 & 92 & 88 & 93 & 74 & 78 & 62 \\
\hline $3-c$ & 83 & 95 & 98 & 87 & 71 & 80 & 79 \\
\hline $3-d$ & 81 & 96 & 73 & 62 & 78 & 77 & 75 \\
\hline $3-e$ & 95 & 98 & 92 & 80 & 72 & 80 & 78 \\
\hline $3-f$ & 85 & 88 & 98 & 72 & 77 & 84 & 89 \\
\hline
\end{tabular}

\section{Results and Discussion}

The reaction between aryl hydrazine and 2(4-chloro phenyloxy)-4,6-dichloro1,3,5-triazine is facile. The products (3a-f) are dark yellow amorphous powders. The C,H,N contents of all (3a-f) shown in Table-1 are consistent with the predicated structures shown in Scheme-1. The IR spectra of all (3a-f) are almost identical. All the IR spectra comprises following important features.

1. -NH-NH- (hydrazine group) : $3280,1610,820 \mathrm{~cm}^{-1}$

2. $s$-triazine $: 1510,1250,870 \mathrm{~cm}^{-1}$

3. -NH- (secondary) $: 3400 \mathrm{~cm}^{-1}$

4. Aryl-O-Aryl : $: 1200 \mathrm{~cm}^{-1}$

As the compounds (3a-f) except $3 \mathrm{e}$ are insoluble $\mathrm{CDCl}_{3}$, the NMR spectral study attempted for $3 \mathrm{e}$. The NMR spectrum of $3 \mathrm{e}$ comprises the multiplet between 6.9 to $8.1 \delta \mathrm{ppm}$ mainly due to aromatic protons. While the signal at $2.6 \delta \mathrm{ppm}$ with integration of $6 \mathrm{H}$ is responsible for two $\mathrm{CH}_{3}$ of $\mathrm{OCH}_{3}$ groups. The signals in most downfield $(9.5 \delta \mathrm{ppm})$ is from NH-NH protons. The result of antimicrobial screening showed (Table 2) that compounds 3a,b,c,f displayed a high order of antibacterial activity and remaining compounds showed weak to moderate activity against both the bacteria. Similarly compounds $3 \mathrm{a}, \mathrm{d}$, and $\mathrm{f}$ showed higher antifungal activity and remaining compounds displayed moderate antifungal activity against the fungi.

\section{Conclusions}

The synthesis of aryl hydrazine-s-triazine is facile. The produced compounds have good microbial toxicity. Due to NH-NH groups these compounds can be utilized for epoxy resin hardner. Such work in polymer journal will be published shortly.

\section{Acknoledgements}

Thanks to Dr.M.V.Hathi, honorary scientist science college, Palanpur, North Gujarat, for permission to extend his work. The authors are also grateful to 
Dr.N.S.Mistry for carry out antimicrobial acticity. One of the author (JAC) is also thankful to Jupiter dye chem. Vapi for carry out research work. Also grateful to the principal Dr.Vimal S Joshi for permission to carry out the research work.

\section{References}

1. Sherman S, Ganon J, Buchi G, Howell K O and Eneyel W R, Chem. Tech., Epoxy Resins, Jhon Wiley and inc. New York, 1980, 9, 267.

2. Freeman H S and Esancy J F, Colour Chemistry, Elsevir, London and New York 1991.

3. Smolin E M and Rapopret L, S-Triazine and derivatives interscience New York, 1954.

4. $\quad$ Patel B R, Patel A M and Patel G A, Oriental J. Chem, 2001, 17(3) 523.

5. Chaudhari J A, Hathi M V and Patel R P, E-J.Chem, 2006, 3, 298-302.

6. Faguda T, Avdv. Exptl. Pathol. Pharmakol, 1932 164, 585.

7. Barry A L, The antimicrobial susceptibility test : Principle and practices, $4^{\text {th }}$ Ed. Philandelphia, 1976,180-193. 


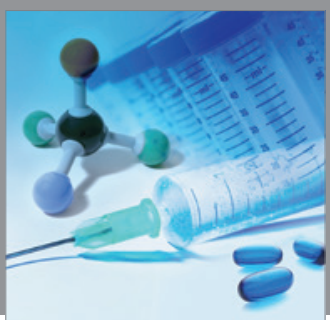

International Journal of

Medicinal Chemistry

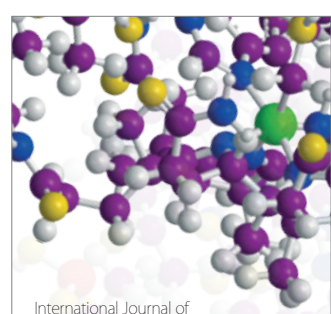

Carbohydrate Chemistry

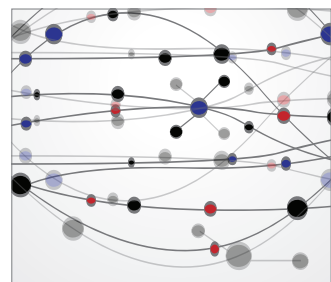

The Scientific World Journal
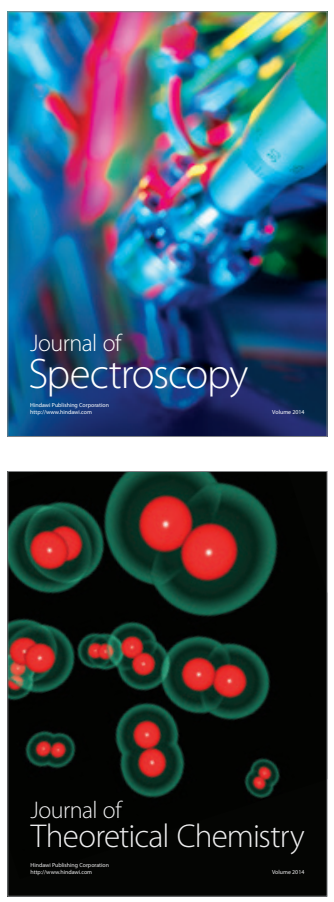
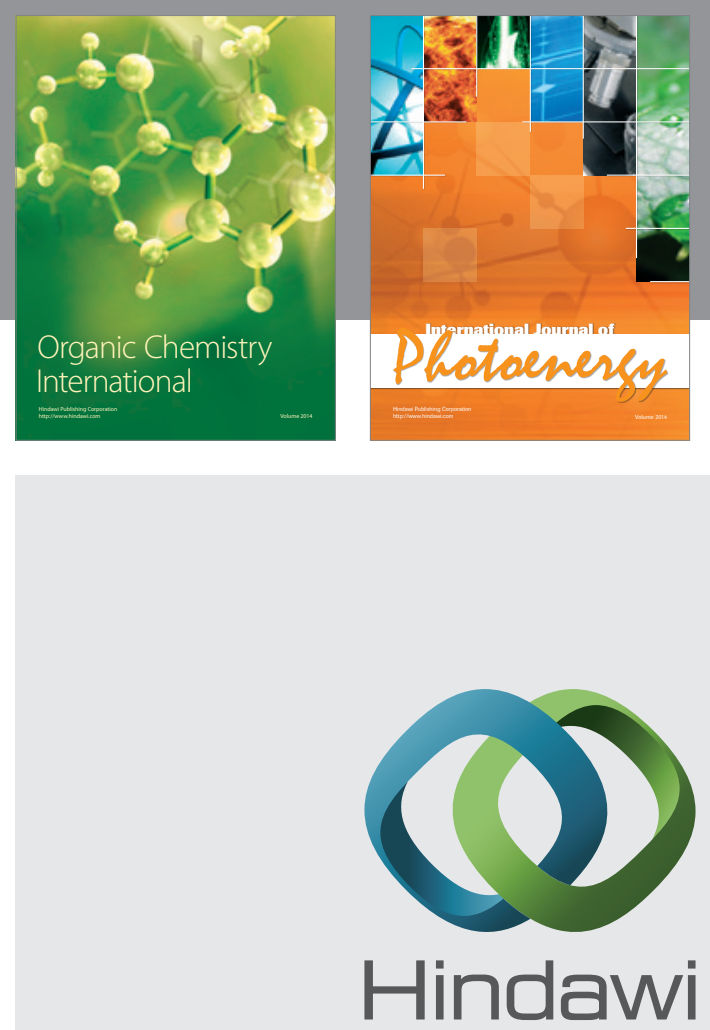

Submit your manuscripts at

http://www.hindawi.com
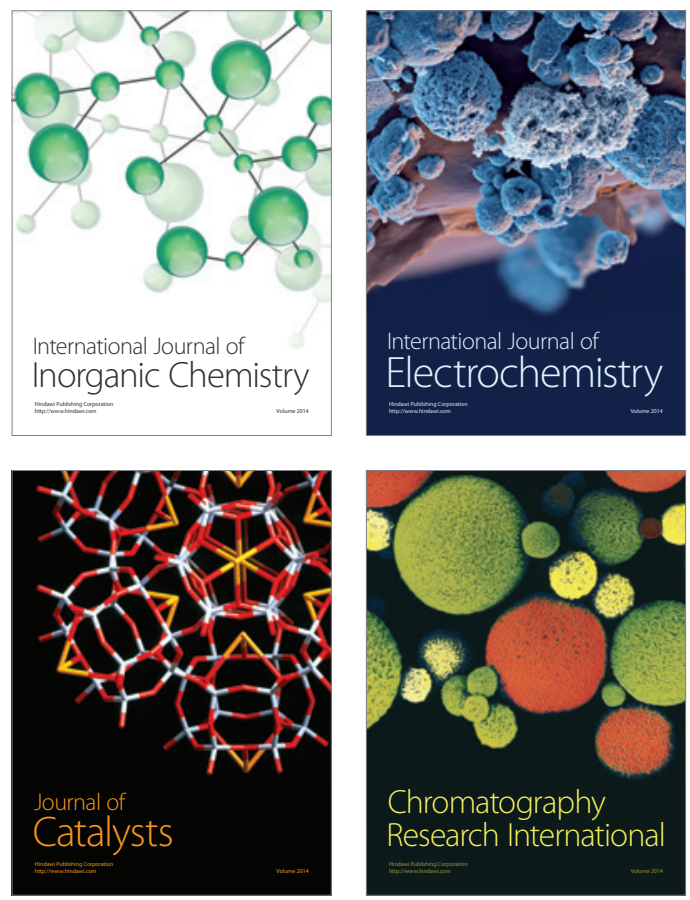
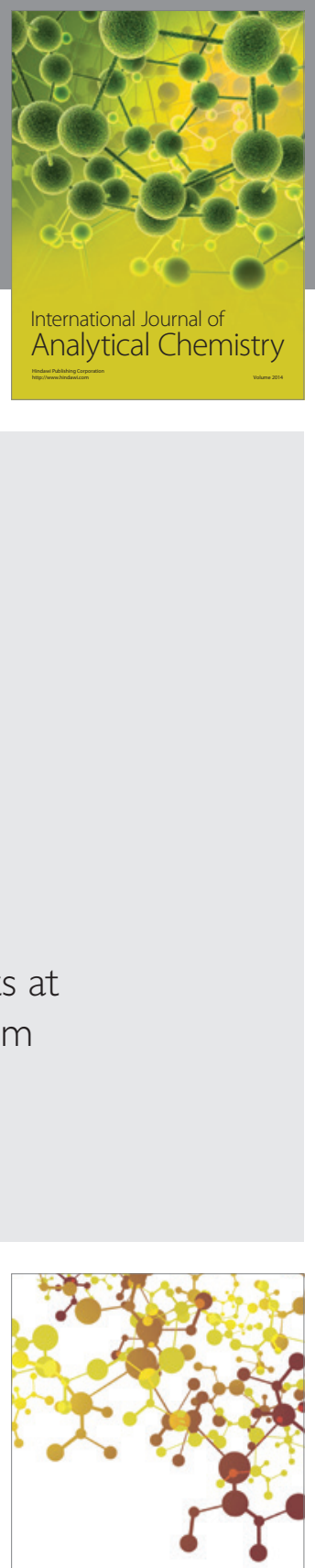

Journal of

Applied Chemistry
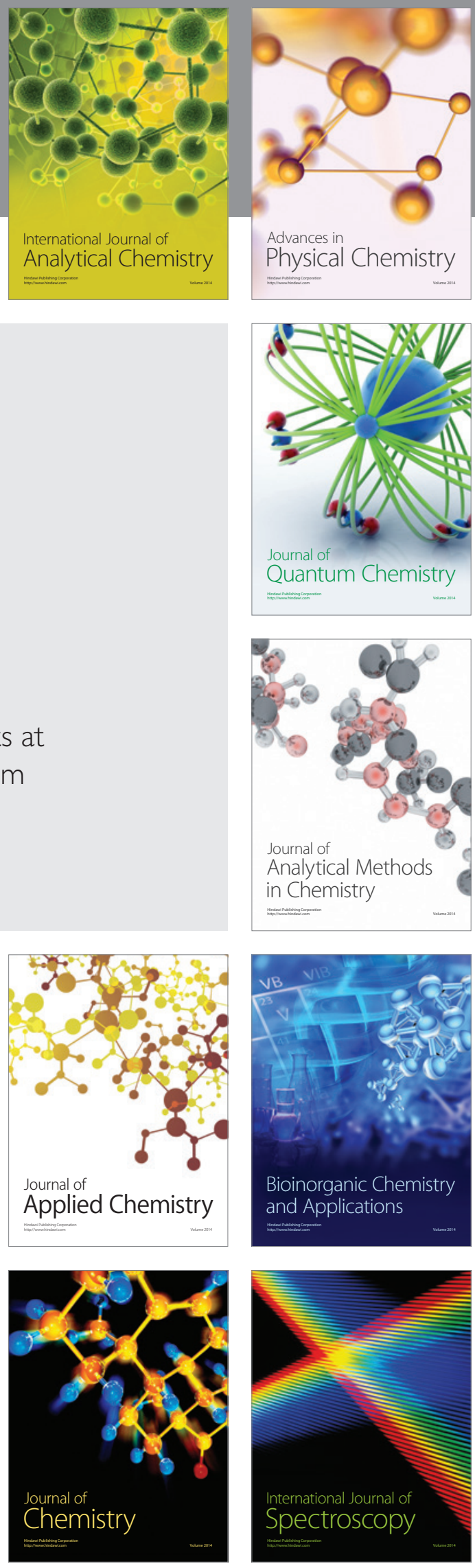